\title{
Study on Development Strategies of Fresh Agricultural Products E-commerce in China
}

\author{
Xiaodong Liu ${ }^{1} \&$ John Walsh ${ }^{2}$ \\ ${ }^{1} \mathrm{PhD}$ Candidate, School of Management, Shinawatra University, Thailand \\ ${ }^{2}$ Lecturer, International Business, RMIT, Vietnam \\ Correspondence: Liu Xiaodong, PhD Candidate, School of Management, Shinawatra University, Thailand.
}

\author{
Received: June 20, 2019 \\ Accepted: July 12, 2019 \\ Online Published: July 18, 2019 \\ doi:10.5539/ibr.v12n8p61 \\ URL: https://doi.org/10.5539/ibr.v12n8p61
}

\begin{abstract}
With the improvement of living standards in China and greater interest in health and nutrition, fresh agricultural products have become the fourth largest category of products sold online in the country after books, electronic products and clothing. They are characterized by high purchase frequency and high profitability. In recent years, e-commerce websites for fresh agricultural products in China have grown rapidly but many of them are difficult to use. Based on the examples of fresh agricultural products e-commerce development in developed countries, this paper analyzes the development problems of the sector in China and puts forward four suggestions: strengthening the construction of agricultural informatization; improving the legislative mechanism of supervision; establishing specialized e-commerce websites for fresh agricultural products and strengthening personnel training.
\end{abstract}

Keywords: China, development strategy, e-commerce, fresh agricultural products

\section{Introduction}

In recent years, the development of e-commerce in China has resulted from the popularity of mobile internet applications, the gradual formation of consumer online shopping habits and the general improvement in the e-commerce user experience. E-commerce development has now gradually moved into the field of fresh agricultural products. Especially since 2012, traditional offline supermarkets, e-commerce enterprises and internet investors have begun to attach importance to the e-commerce of fresh agricultural products and increased exploration and investment in it. Meanwhile, economic development in China has entered a period of deep adjustment. At the national level, policy support has been issued for agricultural e-commerce and the rapid development of this sector has played an important role in innovating the circulation mode of agricultural products and solving the problems of agriculture, countryside and farmers, especially in terms of the development of rural economy, the optimization of agricultural industrial structure and the transformation of the rural production model.

With the rapid development of e-commerce of fresh agricultural products, the academic research on it is also deepening. Many scholars have conducted research on e-commerce transaction mode, channel differences, optimization measures and development trend of fresh agricultural products (e.g. Geng, Ren \& Wang, 2007; Li, $\mathrm{Fu} \& \mathrm{Li}, 2007)$. This has been aimed at solving problems such as additional electricity generation and the development strategy of fresh agricultural product e-commerce with a focus on the online to offline $(\mathrm{O} 2 \mathrm{O})$ model application and the development of cold chain logistics. Shen (2013) analyzed the countermeasures of fresh product e-commerce development from the product, logistic and governmental aspects and found that the government should improve the relevant laws and regulations gradually, support agricultural products upgrading actively and improve the quality of cold chain logistics. Du, Yu \& Han (2014) pointed out that the main difficulties faced by fresh product e-commerce are the excessive initial investment capital, high cost of logistics, low efficiency of delivery and the high cost and loss rates of fresh products in China. They believed that the following countermeasures should be taken: proprietary cold chain distribution, improving the supply chain, centralizing category management, large scale of original purchase, improving the product quality and enhancing the customer experience. Combined with the current bottleneck of the development of fresh product e-commerce, fresh agricultural product e-commerce needs reasonable positioning. Through a process of SWOT analysis, Five Forces model analysis and profit model analysis, Li (2014) proposed the development of fresh agricultural 
product e-commerce in China. On the macro level, the main issues are to strengthen the development of agricultural standardization, promote the quality and safety of agricultural products and agricultural scale management and, finally, establish the relevant laws and regulations for fresh agricultural product e-commerce. On the micro level, it is necessary to improve the low-end fresh agricultural product standardization, innovate the marketing model and enhance awareness of consumer consumption habits. Tang (2014) pointed out that, at present, there are three common problems in fresh agricultural product e-commerce in China, which are cold chain logistics construction, choice of business model and how to improve consumer trust in fresh agricultural product e-commerce providers. Consequently, the future of fresh agricultural product e-commerce development cannot be separated from the scale of the third party cold chain logistics companies. Zhang (2014) analyzed the concept, origin, development process, development status and development difficulties of fresh agricultural product e-commerce and also proposed recommendations accordingly. Gu (2016), meanwhile, suggested improving the quality of supply chains and logistics efficiency in China.

However, as agricultural e-commerce involves agricultural production, processing, logistics, marketing and website construction, it is difficult to operate and government support and supervision is also difficult to manage. China's agricultural products in the overall proportion of online retail is still very small. The influence of websites specializing in fresh agricultural products e-commerce is also very limited. Nevertheless, in recent years, platforms, supermarkets and agricultural bases have entered the market, although many of them have struggled and there is a high bankruptcy rate. Data shows that, in2017, there were more than 4,000 fresh agricultural products e-commerce enterprises in China, with only $1 \%$ of them being profitable, $4 \%$ breaking even, $88 \%$ having a slightly deficit and $7 \%$ having a large deficit.

Based on the above introduction, this paper summarizes the characteristics and experience of e-commerce development of fresh agricultural products in many developed countries, while analysing the main problems and countermeasures of e-commerce development of the sector. This has important practical significance for grasping the development trend of e-commerce of fresh agricultural products in China and ensuring the healthy and sustainable development of e-commerce in fresh agricultural products.

This paper uses a critical-analytical case study approach that identifies policies and practices used in other countries with a view to trying to understand how they might be adapted to the Chinese context. Normative recommendations are drawn from this approach.

\section{The Experience of Fresh Agricultural Products E-Commerce in Developed Countries}

\subsection{USA}

The USA was the first country to start e-commerce in fresh agricultural products. It established a complete system for collecting and publishing market information on fresh agricultural products. The Department of Agriculture's Fresh Agricultural Products Sales Bureau is responsible for this work and it publishes market information of fresh agricultural products free of charge through various network channels. Agricultural operators can consult real-time market information of fresh agricultural products on the Internet and find trading objects and times, so as to improve greatly the commercial operational efficiency of the agriculture industry. The U.S. government has also promulgated sound agricultural informationization laws and regulations and strengthened the supervision of the authenticity of agricultural information to ensure its accuracy, relevance and intellectual property rights issues, promote information sharing and protect the rights and interests of information providers. The U.S. government has established a mature, strict and perfect standard system for fresh agricultural products in various agricultural production technologies and production norms, as well as a relevant standard supervision system. The quality standardization system and strict supervision system of fresh agricultural products in the U.S. have improved consumers' confidence in e-commerce in this sector and promoted the development of agricultural e-commerce. Local Harvest, Farmigo and Amazon Fresh are the representative enterprises of fresh agricultural product e-commerce in the U.S. Local Harvest, an e-commerce platform connecting small and medium-sized farms, CSA (Community Supported Agriculture) farms and consumers in the U.S., adopts the interactive mode of "platform+farm+ marketing. " Its greatest feature is the interactive mode between producers and consumers. That is, consumers can obtain local farm agricultural product information through the map retrieval system on the Local Harvest website and orderproducts directly. Farms can publish information about farm activities such as field trips, school farming and festivals on the Local Harvest website, so that interested consumers can participate in agricultural practice. Farmigo is a third-party agricultural product online trading platform connecting farms and community consumers. Farmigo operates under the mode of $\mathrm{O} 2 \mathrm{O}+\mathrm{B} 2 \mathrm{C}$ (business to customer) community-oriented diversion, forming a unique mode of community group purchase, that is, collecting residents' agricultural demand through food community leaders and then producing 
and distributing via local or neighboring farms according to community orders. The information between producers and consumers is effectively linked up, and its localization ensures the freshness of agricultural products and reduces the cost of warehousing and logistics. AmazonFresh, as Amazon's fresh product operating platform mainly sells its own agricultural products through Amazon's own fresh logistics distribution. AmazonFresh is also facing the problem of the high cost of self-owned cold chain logistics. AmazonFresh has since adopted a more robust expansion. In 2007, it began to provide services in two residential areas of Seattle, expanded throughout Seattle after five years and then expanded to four more cities in the United States after seven years. This has enabled the company not only to avoid excessive financial pressure but, also, constantly improve the business model to better ensure the quality of fresh agricultural products.

\subsection{Germany}

With the development of B2C e-commerce in Germany, the overall scale of agricultural e-commerce in Germany has also been showing a growing trend. Data released by Eurostat and German B2C E-Commerce Report 2016 show that the online transaction volume of German primary agricultural products e-commerce increased from 9.566 billion euros in 2012 to 17.282 billion euros in 2016, showing a continuous upward trend in the past five years, with an average annual growth of $15.94 \%$. The popularization of computers and the Internet has underpinned the rapid development of German agricultural e-commerce. The German agricultural information system is sound and computer networks, 3S technology (geographic information system, global positioning system and remote sensing) and other modern information technology applications are widely used. Government, associations, companies, universities and other organizations jointly participate in the formation of a diversified, multi-level information service pattern. Agricultural information service centres have been set up in the agricultural sector of the German government to provide free information services on agricultural laws, policies, standards, disasters, management and supply and demand trends of agricultural products to farmers, rural residents, agricultural distributors and processing enterprises. In 2012, in order to improve the production efficiency of small and medium-sized enterprises, Germany subsidized 1.9 million euros for e-commerce, covering many public areas such as e-commerce, standardization, Geobusiness, product-friendly design, information security, data compatibility and so on, thus realizing the whole process of service. The German government considers the development of agricultural e-commerce to be of central importance and is mainly involved in planning and construction of agricultural information technology facilities. The government has invested in the construction of agricultural e-commerce websites for some farms and farmers, thus reducing their operating costs. In addition, the German government has vigorously promoted the informatization of agriculture and the food industry, trained farmers in innovation and to use the network and develop e-commerce technology, while also attracting more agricultural producers to participate in agricultural e-commerce activities. At present, the e-commerce of agricultural products in Germany is developing in the direction of specialization. The existing e-commerce platforms can be divided into two main types: information consultation and electronic transaction, according to their different markets and user positioning. The former mainly includes various kinds of agricultural electronic information service websites, such as the information service websites represented by the German Ministry of Agriculture Information Network and the agricultural-related websites established by local governments at all levels. Its goal is to realize the network dissemination of market information, providing agricultural market information and agricultural production consultation information. The latter mainly includes the electronic trading platforms of large-scale agricultural products and electronic stores. It aims to realise the electronic trading of agricultural commodities, focusing on the online trading of agricultural products, the agricultural means of production and provision of agricultural services.

\subsection{Japan}

The application of emerging technology has always been a characteristic of Japanese e-commerce. In the early 1990s, Japan established the national online network of an agricultural technology information service, which can collect, process, store and transmit agricultural technology information from all parts of the country in a timely manner. There are sub-centres in all counties and some subsidies are given to farmers who buy computers. Various training courses are also held to improve farmers' knowledge of the network, master the network and use the network skills. In 2001, Japan formulated the "21st Century Rural Informationization Strategy." By improving the coverage of rural optical fibres, establishing an information platform for agricultural products and training agricultural informationization personnel, this has further narrowed the gap between urban and rural informationization and, also, helped rural areas develop agricultural production by utilizing information resources. In 2004, the Japanese government issued the "Agricultural Internet of Things Program," led by NEC, Fujitsu, Hitachi, Mitsui and other large companies. Through the establishment of wireless networks, soil sensors, sunshine sensors, temperature sensors, carbon dioxide emission sensors and other management centres in 
farmland greenhouses, farmers can monitor and control fertilization, watering and temperatures in real time by using computers or mobile phones. By 2014, more than half of Japanese farmers had used the agricultural Internet of Things technology. It is expected that the scale of agricultural informatization in Japan will reach 60 billion yen by 2020. In addition, the Japanese government actively safeguards the rights and interests of the main body of agricultural products trading and promotes information sharing and has established a sound legal system of agricultural products e-commerce. The Basic Law on Food Safety promulgated in 2003 clarifies the responsibilities of the government, local public organizations and relevant practitioners in ensuring the quality and safety of agricultural products and establishes the Food Safety Committee as the supreme regulatory body in the Cabinet. The Law on Quality Specifications and Correct Marking of Agricultural and Forestry Products stipulates the packaging and marking standards of agricultural products, which provides convenience for consumers to master relevant high quality information on agricultural products. In 2015, the Food Marking Law and the Livestock Infectious Disease Prevention Law were implemented, which contained comprehensive provisions on animal breeding and epidemic prevention, epidemic situation notification, epidemic culling, innocuous treatment, financial compensation and legal liability of the government and breeders. At present, there are various types of e-commerce platforms for agricultural products in Japan, which can be divided into four categories: comprehensive online supermarkets, large-scale comprehensive online trading markets, agricultural electronic exchanges and specialized online stores for agricultural products. Oisix ra Daichi is a typical representative of fresh agricultural products e-commerce in Japan. As an e-commerce company in Japan, Oisix ra Daichi is set up by farmers, employees and some consumers. It has signed purchase agreements with farmers to study and solve technical problems together. Consumers can sign contracts with their designated farmers and become contract signers. The greatest advantage of this model is that it realizes the integration of interests of farmers, employees and consumers and significantly strengthens the trust relationship between farmers and consumers.

\subsection{Other Developed Countries}

In addition to the USA, Germany and Japan, other developed countries also attach great importance to the research and development of agricultural e-commerce. Canada uses modern information technology such as computer networks and $3 \mathrm{~S}$ technology to improve its agricultural information system. At the same time, it has established an agricultural information service centre to provide free information services to producers and sellers of agricultural products, such as agricultural laws and regulations, management and supply and demand trends of agricultural products. The Netherlands, which is the third largest exporter of agricultural products in the world, carries out electronic auctions of agricultural products in the field of e-commerce by virtue of unified national agricultural standards and a developed agricultural logistics system. South Korea has actively trained farmers to use the network in the development of agricultural e-commerce, reducing transaction costs and improving the circulation speed of agricultural products. With the development of agricultural mechanization and industrialization, Australia has effectively improved the supply capacity of agricultural products and, with the advantage of economic development, all farmers can use computers to connect to the network.

\subsection{Main Characteristics of Fresh Agricultural Products E-commerce Development in Developed Countries}

Through summarizing the development of e-commerce of agricultural products in developed countries, it can be found that the main characteristics of the development of e-commerce of fresh agricultural products are as follows:

\section{Agricultural Informatization Construction}

The popularization of computers and the internet is the basis and guarantee for the rapid development of e-commerce for fresh agricultural products. Agricultural information service centres have been set up in agricultural departments of developed countries to provide information services on agricultural laws, policies, standards, disasters, management and supply and demand trends of agricultural products to farmers, rural residents, agricultural product distributors and processing enterprises. They can get the information of supply and demand situation and sale price of agricultural products at home and abroad in time from the system, get orders directly on the internet and adjust the variety, quantity and price of production according to their own conditions, so that production is in a highly orderly state. 


\section{Government Supervision Legislation}

Owing to the characteristics of fresh agricultural products, it is necessary for the government to formulate and improve relevant laws, regulations and policies through various channels such as food safety, e-commerce, consumer protection, economic market operation and so on. In particular, the German government has established a Food Safety Agency, which is responsible for formulating food safety measures at the federal level and for monitoring market trends in collaboration with the responsible agencies of the Federal States. At the same time, Germany has formulated a standard system for the classification and grading of agricultural products, which effectively guarantees the quality of agricultural products sold online and is conducive to standardizing and promoting the healthy and orderly development of agricultural e-commerce. Japan has promulgated the Basic Law on Food Safety, which clarifies the responsibilities of the government, local public organizations and relevant practitioners in ensuring the quality and safety of agricultural products, and has set up a Food Safety Committee as the highest regulatory body in the Cabinet. In addition, the Law on Quality Specifications and Correct Marking of Agricultural and Forestry Products has been promulgated, which stipulates the packaging and marking standards of agricultural products and provides convenience for consumers to grasp the relevant quality information of agricultural products. Through the law on the quality and safety of agricultural products, the production, processing and circulation of fresh agricultural products are managed according to law, which ensures the quality and safety of agricultural products entering the field of electronic commerce.

\section{Infrastructure Construction}

As the production centre of fresh agricultural products, the countryside is an important base for the development of e-commerce platform. Consequently, it is essential to develop various forms of information transmission equipment, build information transmission networks and strengthen a series of infrastructure construction projects such as rural network information. The U.S. government focuses on macro-control of the development of agricultural e-commerce and is committed to providing the public resources needed for market development, such as broadband construction in rural areas and the construction of transportation and logistics infrastructure. Every year, the U.S. government has allocated special funds to ensure the smooth operation of its agricultural e-commerce platform. Like other developed countries, the German government puts the development of agricultural e-commerce as a central priority, mainly the planning and construction of agricultural information technology facilities. The government invests in the construction of agricultural e-commerce websites for some farms and also attaches great importance to long-term investment in agriculture, agricultural research and development and rural education projects to provide farmers with professional and authoritative information services.

\section{Current Status of E-commerce Development of Fresh Agricultural Products in China}

\subsection{Development Course}

The development of fresh agricultural products e-commerce in China has gone through three stages: beginning period, exploration period, and development period.

\section{Beginning Period (2005-2012)}

The scope of e-commerce trade of agricultural products in China has expanded and the main varieties of trade have changed from grain products to fresh agricultural products. Under the stimulation of the huge consumer market, a large number of e-commerce websites for fresh agricultural products have emerged. However, too many businesses have entered the industry, resulting in the emergence of an industry bubble. At this stage, the operation model of fresh agricultural products e-commerce only replicates the model of ordinary e-commerce and, eventually, many enterprises have failed.

\section{Exploration Period (2012-2013)}

This was a milestone year for the development of e-commerce for agricultural products in China. The development of social media and mobile internet applications has given fresh e-commerce more modes of exploration. The two major Chinese e-commerce giants, Alibaba Group and Jingdong Mall, have accelerated the exploration of rural e-commerce. In addition, the large-scale e-commerce websites of fresh agricultural products, such as Tootoo.cn and Benlai.com, have obtained venture capital.

\section{Development Period (2013-)}

After 2013, the e-commerce development of fresh agricultural products in China has accelerated, showing a diversified trend. Many business models have begun to emerge, such as $\mathrm{B} 2 \mathrm{C}, \mathrm{C} 2 \mathrm{C}, \mathrm{C} 2 \mathrm{~B}$ and $\mathrm{O} 2 \mathrm{O}$ (online to offline). Advanced information technology and modern communication tools such as micro-blogs, 
micro-messaging, Internet of Things and cloud computing have become widely used. Fresh agricultural products have become a hot spot of large-scale e-commerce websites, entering the peak period of financing.

\subsection{The Scale of Market Development}

With the rapid development of the Internet, the number of Chinese netizens is increasing year by year and the internet industry continues to develop steadily. The internet has become an important force to promote China's economic development. According to the statistics of China Internet Network Information Centre, as of December 2017, the number of Chinese netizens reached 772 million, with a total of 40.74 million new netizens added throughout the year. Fresh agricultural e-commerce market has developed rapidly in China with an average annual growth rate of more than 50\%. In 2017, fresh agricultural products market transactions amounted to 1789.7 billion-yuan, fresh agricultural products e-commerce market transactions amounted to 141.8 billion-yuan, online market penetration continued to improve, reaching 7.9\%. It is estimated that the transaction scale of fresh e-commerce market will reach 215.8 billion yuan in 2018. According to the forecast of the China Business Industry Research Institute, the compound growth rate of fresh e-commerce market will reach $49 \%$ in the next three years and the penetration rate of the online market will continue to increase, reaching $21.7 \%$ by 2020 .

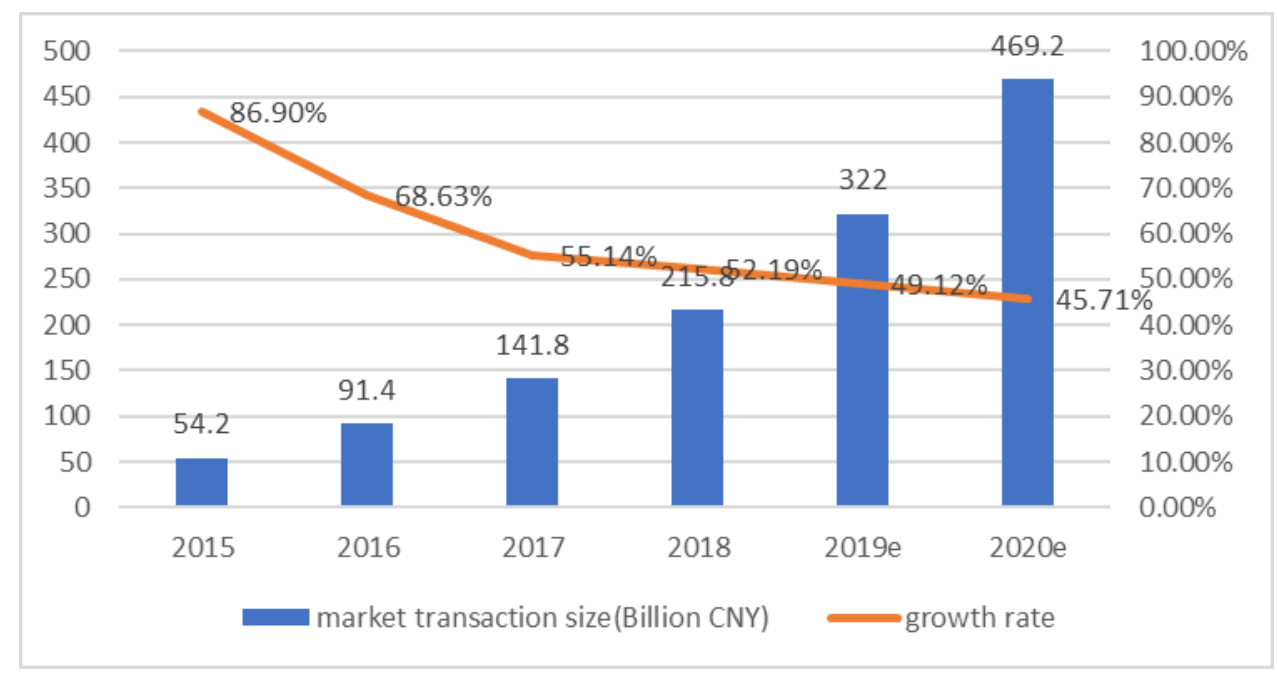

Figure 1. 2015-2020 Fresh Agricultural Products E-commerce Market Transaction Size in China Source. China Business Industry Research Institute. 2018

\subsection{Business Model Innovation}

The current mainstream fresh agricultural products e-commerce models in China are based on the B2C model. In particular, many innovation models are derivatives of the B2C. Owing to the particularity of fresh products e-commerce, relying only on a traditional B2C model makes it obviously difficult to deal with new developments, which should be combined with the need to cater to market demand that is changing. Iresearch.com, a consulting group, classified fresh e-commerce models into three categories: fresh category of e-commerce platforms; integrated B2C fresh e-commerce models and vertical B2C fresh e-commerce models, according to its report "2013 Fresh E-commerce Development Briefing." In the "2013 China Fresh Electricity Supplier Status Survey Report" by the China E-commerce Research Centre, it classified fresh products e-commerce models into four categories: integrated e-commerce platform models; vertical e-commerce models; logistics e-commerce models and $\mathrm{O} 2 \mathrm{O}$ e-commerce models.

By referring to the classification of fresh e-commerce business models in the literature and taking different business models into account, this research points out that fresh e-commerce models can be classified into integrated e-commerce platform models, vertical e-commerce models and $\mathrm{O} 2 \mathrm{O}$ e-commerce models. Meanwhile, according to different operational entities, vertical e-commerce models can be classified into logistic e-commerce, supplier e-commerce models and professional localization e-commerce. $\mathrm{O} 2 \mathrm{O}$ e-commerce models can be classified into offline supermarket models and community $\mathrm{O} 2 \mathrm{O}$ models and the case analysis of the characteristics of each model is shown in the following figure 2 . 


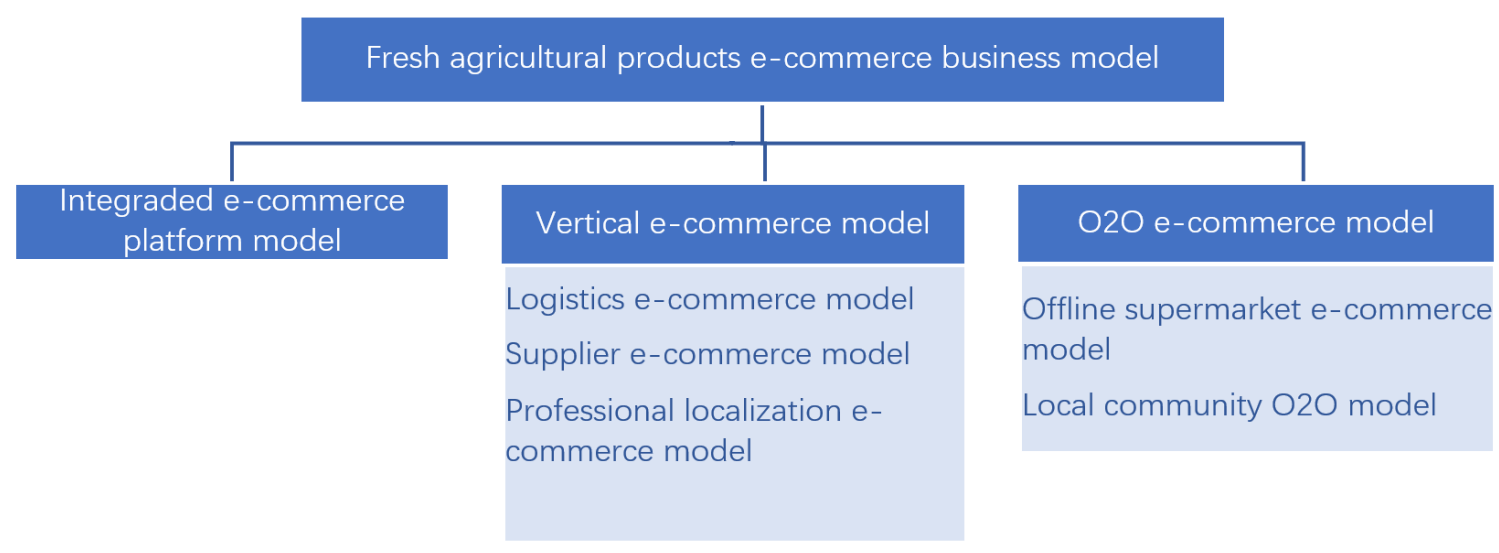

Figure 2. Classification of Fresh Agricultural Products E-commerce Business Models in China

In 2017, there were nearly 4000 e-commerce platforms for agriculture related transactions in china. Taobao.com, Yhd.com and Jingdong.com all have strong positions in the retail network of agricultural products that belong to the integrated e-commerce platform model. The model is mainly to attract all kinds of fresh manufacturers or farmers to incorporate online shop in their own platforms. Settled manufacturers or farmers are responsible for the products and the cold chain distribution by themselves. The platform is only responsible for supervision. This e-commerce platform is designed for the operation of the whole category, which includes fresh products. So, based on customers' stickiness, the platform suppliers have to operate fresh products, although fresh product is a kind of strategic loss-making category at present.Womai.com is a typical representative of a vertical e-commerce model. At present, vertical fresh agricultural products e-commerce websites are mainly focused on food. All products on the vertical fresh e-commerce platform are provided by the supplier. The quality of the products is guaranteed by the platform. Its logistics is mainly based on platform self-distribution and part of the vertical fresh vertical e-commerce also cooperates with the third-party logistics operation to reduce the loss of products in the logistics activities. However, based on cost and other considerations, the vertical fresh e-commerce platform operates its business only in particular areas or cities.O2O refers to combinations of business opportunities from both offline and the internet and it makes the internet become a new trading platform. In the fresh agricultural products e-commerce area, $\mathrm{O} 2 \mathrm{O}$ e-commerce is still in the early stages of construction in China.

\section{Development Problems of Fresh Agricultural Products E-commerce in China}

\subsection{Agricultural Informatization Construction Lags behind}

Owing to the unbalanced degree of informatization in different areas of China, the construction of agricultural informatization in rural areas lags behind. For a long time, due to limited investment, the construction of agricultural information infrastructure has been weak and the rural information network and communication system is not perfect. Although the pattern of unified collection and release of agricultural information in China has initially taken shape, the processing, analysis, utilization and market cultivation of agricultural information have all developed slowly. The agricultural information service is insufficient and its structure is unbalanced, which leads to poor decision-making in agricultural production. In addition, in the current process of building e-commerce platforms for agricultural products, the major e-commerce platforms have no norms and standards in the construction of information systems, which makes it difficult to unify and integrate data and, so, it is not possible to provide guidance for agricultural production and this causes a waste of information resources. At the same time, due to the lack of data integration and publicity, farms, scholars and relevant policy-making departments cannot effectively use these data to cross-reference and obtain reliable research conclusions, business decisions and policy recommendations. 


\subsection{Disadvantages in Legislation and Supervision Mechanisms}

At present, China has not yet promulgated a special law on the e-commerce of agricultural products and there is a lack of legal supervision on trading activities. It is urgent to fill this legal gap. In addition, the standard system of products, packaging, distribution and quality of agricultural products e-commerce is not perfect and the national unified traceability system of agricultural product quality and safety has not yet been established. The lack of credibility of agricultural product quality increases the difficulty of agricultural product sales. Standardization of agricultural products has basically been popularized in developed countries. As early as 1997, Japan formulated electronic trading standards for fresh food. Although standardization has been achieved to some extent in China, there is still a big gap between China and developed countries. This is mainly reflected in the following aspects: first, the construction of agricultural standardization in China lags behind and the number of agricultural products standards is far less than that in developed countries; second, the implementation of existing standards is inadequate - because standardized production is more expensive, many farmers will violate production in consideration of immediate interests. These two situations will bring the consequences of information asymmetry to fresh agricultural products e-commerce, which seriously affects its development.

\subsection{E-commerce Operation ModelIs Inefficient and Unsustainable}

At present, there are three main problems in the operation mode of e-commerce for fresh agricultural products in China. First, in terms of the main competitors, it is shown to be oligopolistic competition. At present, the main competitors in the fresh agricultural products e-commerce market are Alibaba, Jingdong and Suning. Second, there is a big gap in the quality of agricultural products. Owing to the unmatched cold chain and the imperfect construction of the whole cold chain, it is difficult to sell high-quality agricultural products and the low-cost promotions make the costs difficult to recover. Third, low-price competition has resulted in the prevalence of inferior products and poor after-sales service quality. Most e-commerce enterprises focus on increasing sales volumes and profits through low-cost competition but do not reduce costs from the perspective of platform integration and maximizing the interests of all parties, which has become a major constraint for the construction of the whole industry chain. In the aspect of perfecting and innovating the supply system of agricultural products, e-commerce enterprises have not established strategic cooperative relations with the suppliers of agricultural products (production enterprises, cooperatives and farmers), nor have they formed the accountability and supervision mechanismsfor all stakeholders. There are fewer sales links in fresh agricultural products e-commerce than traditional sales methods but there are huge costs in the construction of logistics infrastructure, resulting in no competitive advantage in the final price of products. Such an operation strategy is not commensurate with the sustainable development of rural e-commerce. In addition, China's e-commerce industry chain construction of agricultural products lacks the competitive brand of agricultural products, the quality of after-sales service is not high and there is no consumer demand-oriented agricultural production and marketing system. Taking Alibaba Group as an example, more than $95 \%$ of the merchants mainly focus on Taobao, Tmall and such platforms for time-limited and ultra-low-cost sales and there is no effective docking between rural e-commerce platforms and processing. At the same time, another reason for the low quality of after-sales service and the difficulty of service system innovation in rural e-commerce is the lack of high-quality service providers and the inadequate training of relevant practitioners.

\section{The Strategies of E-commerce Development of Fresh Agricultural Products in China}

\subsection{Strengthening the Construction of Agricultural Informatization}

In rural areas of China, especially in the western mountainous areas, the network infrastructure is still relatively weak and the internet penetration rate is relatively low. The German government has established a wide coverage and strong guidance information service system for agricultural products, which ensures agricultural production takes place in a highly orderly state, realises the seamless connection between production links and consumer markets and is conducive to the development of e-commerce activities for agricultural products. Japan has strengthened the construction of agricultural informationization by implementing the "Highly Informationized Rural System Plan," "National Online Network of Agricultural Technology Information Service," "21st Century Rural Informationization Strategy" and "Agricultural Internet of Things Plan," which has laid a solid foundation for the development of agricultural e-commerce. At present, China should establish a government-led network information service system for agricultural products, provide farmers with timely, comprehensive and accurate market information for agricultural products and expand and improve the management and service functions of the agricultural supply chain. In order to standardize the work of each agricultural product information publishing subject, the government should also set up a special coordinating body and establish a coordinating mechanism for information publishing, so as to ensure the agricultural product information has different 
emphases on the content and detail of publishing, improves the effectiveness and pertinence of information transmission and better meets the needs of personalized information.

\subsection{Improving the Legislative Mechanism of Supervision}

China should constantly improve the legal system of e-commerce for agricultural products from the aspects of network security, information technology and product quality and safety. In the e-commerce activities of fresh agricultural products, consumers' rights and interests are vulnerable to infringement and it is difficult to safeguard their rights, which seriously affects consumers' participation in the new consumption mode of e-commerce of agricultural products. Consequently, on the basis of "Consumer Rights Protection Law" and "Contract Law," China should add consumers' privacy rights and protection content and properly extend the right to know, so as to maximize the protection of online consumers' rights and interests. In addition, China should take the "Law on the Quality and Safety of Agricultural Products" as the core, improve the supporting laws and regulations, promote the conformity of the quality and safety standards of agricultural products with international standards and implement supervision of and responsibility for the subject. A multi-level supervisory system with strong operability and complete and rigorous legal system should be formed to ensure the quality and safety of agricultural products.

\subsection{Establishing Specialized E-commerce Websites for Fresh Agricultural Products}

There are various models of e-commerce platforms for fresh agricultural products in developed countries such as the USA and Japan. which are not only comprehensive O2O supermarkets based on physical stores, combining shop sales with online sales but, also, B2B and B2C e-commerce platforms specializing in online business activities. There are not only large-scale comprehensive network trading markets with complete commodity categories and large sales scale but, also, specialized network stores of agricultural products with community as the centre and offering only fresh vegetables and fruit. The diversification of the e-commerce mode of fresh agricultural products is conducive to its brand and characteristic development and also gives consumers more choice. In recent years, the number of e-commerce websites for fresh agricultural products in China has been increasing but most of them are difficult to operate. Agricultural products are seasonal and regional, perishable, difficult to store and unsuitable for long-term transportation. They have high standards and requirements for production, processing, packaging, warehousing, transportation, handling, distribution and other links throughout the supply chain. Consequently, it is urgent to establish a number of high-quality, comprehensive and specialized agricultural products e-commerce websites to support online listing, online bidding, online negotiation and other trading modes so as to provide consumers with product information, real-time transactions and cold chain transportation services. E-commerce enterprises should establish orderly and cooperative relationships with farmers of origin, control the quality of agricultural products from the source and create stable and smooth sales channels. They should also implement technical standards that meet the requirements of modern logistics, shorten the circulation link of agricultural products and ensure the freshness and high quality of agricultural products, thereby forming a complete industrial chain of "producer to agricultural products e-commerce platform to consumer," which would drive the development of agricultural industrialization.

\subsection{Strengthening Personnel Training}

The development of e-commerce for fresh agricultural products requires a large number of professional practitioners who understand both network technology and network marketing. Although the number of agricultural products e-commerce websites and the number of rural network users have increased significantly in China, the lack of e-commerce professionals is one of the bottlenecks restricting the development of agricultural products e-commerce. Consequently, firstly, China should support e-commerce educational research institutions and e-commerce enterprises to establish e-commerce research and training centres for agricultural products and carry out theoretical research and skills training. Secondly, it should encourage fresh agricultural products e-commerce enterprises to connect with universities in depth, in order to cultivate practical talents and set up agricultural products e-commerce related majors in universities. Thirdly, the local government should actively carry out training on practical knowledge of e-commerce for farmers, improve farmers' understanding of e-commerce, help farmers understand the demand situation and price trend of agricultural products on the market through the network and use the network to promote and sell agricultural products, which can increase farmers' income, stabilize the supply of agricultural products and improve the overall competitiveness of agriculture. 


\section{Conclusions}

The development of fresh agricultural products e-commerce is the development of an industry chain, which will drive the development of production, sales, procurement, finance, marketing, warehousing, logistics and other fields. The most important thing is to provide employment and opportunities for rural residents and also to provide the economic basis and life guarantees for urban residents. At present, the fresh agricultural products e-commerce in China is growing rapidly but it lags behind the developed countries in the aspects of agricultural informatization and legislative mechanism of supervision. In particular, the construction of a standardization system and the specialization and diversification of business operation models are important factors for the sustainable development of e-commerce of fresh agricultural products in China. The research on the development strategies of e-commerce for fresh agricultural products can guide production, alleviate the contradictions between supply and demand, reduce costs and promote the healthy development of e-commerce for fresh agricultural products in China. At the same time, it also provides a theoretical reference for government departments, e-commerce enterprises, industry practitioners and agricultural producers.

The study focuses on the development of e-commerce of fresh agricultural products in China from the macro level. It does not take into account the differences between different and unequal regions of economic development in China. This is also a future research direction of fresh agricultural products e-commerce. It would put forward more detailed solutions for specific areas, which would be beneficial for the construction of Chinese e-commerce infrastructure in rural areas, thereby improving farmers' participation in e-commerce and the diversified development of rural e-commerce in the country.

\section{References}

China E-commerce Research Center. (2013). Agriculture related e-commerce report: OCS farmers income is far more than ordinary farmers. Http://www.100ec.cn/detail--6057206.html (in Chinese).

Du, X. N., Yu, S. H., \& Han, J. L. (2014). Online shopping, fresh product e-commerce industry new explosion point. Operation and Management, 5, 44-46 (in Chinese).

Geng, S., Ren, T. Z., \& Wang, M. H. (2007). Technology and infrastructure considerations for e-commerce in Chinese agriculture. Agricultural Sciences in China, 6(1), 1-10. https://doi.org/10.1016/S1671-2927(07)60010-8

G, Z. (2016). Development status and countermeasures of fresh product e-commerce.Science and Technology Innovation and Application, 27, 279 (in Chinese).

$\mathrm{Li}$, B. (2014). Research on the development of fresh electricity supplier industry (Doctoral dissertation). Graduate School of Chinese Academy of Social Sciences, Beijing (in Chinese).

Li, Y., Fu, Z. T., \& Li, H. (2007). Evaluating factors affecting the adoption of mobile commerce in agriculture: An empirical study. New Zealand Journal of Agricultural Research, 50(5), 1213-8. https://doi.org/10.1080/00288230709510404

Shen, K. H. (2013). Strategy of fresh product e-commerce development in China. Economic Research Guide, 26 , 193-194 (in Chinese).

Tang, Y. (2014). Study on the problem of fresh e-commerce. Electronic Commerce, 8, 3-4 (in Chinese).

Zhang, Z. H. (2014). The development of American agricultural electronic commerce and its enlightenment to China. Electronic Commerce, 9, 115-119.

\section{Copyrights}

Copyright for this article is retained by the author(s), with first publication rights granted to the journal.

This is an open-access article distributed under the terms and conditions of the Creative Commons Attribution license (http://creativecommons.org/licenses/by/4.0/). 